\title{
PENGARUH TRAINING SATISFACTION, SUPERVISOR SUPPORT TERHADAP TURNOVER INTENTION YANG DI MEDIASI OLEH WORK ENGAGEMENT DI DIRJEN BINA PEMDES KEMENDAGRI
}

\author{
Salsabila Rizky Septinia Sari ${ }^{1}$, Indrawan Dona Kumara ${ }^{2}$, Anggun Amanda Endah \\ Pratiwi $^{3}$, Sri Ramadhani Asda ${ }^{4}$, Andreas Wahyu Gunawan ${ }^{5}$ \\ salsabila.septinia@gmail.com ${ }^{1}$, $\underline{\text { indrawandk1006@gmail.com }}^{2}$, \\ anggunamanda73@gmail.com ${ }^{3}, \underline{\text { ramaasda@gmail.com }}^{4}$, $\underline{\text { andreaswg@ } @ \text { trisakti.ac.id }}^{5}$ \\ Fakultas Ekonomi dan Bisnis, Universitas Trisakti \\ Jl. Kyai Tapa No. 1, Grogol, Jakarta Barat, DKI Jakarta 11440
}

\begin{abstract}
ABSTRAK
Penelitian ini bertujuan untuk menganalisis pengaruh Training Satisfaction, Supervisor Support terhadap Turnover Intention yang dimediasi oleh Work Engagement. Penelitian ini dilakukan dengan menyebarkan kuesioner melalui metode pengambilan sampel menggunakan purposive sampling yang melibatkan pegawai Direktorat Jenderal Bina Pemerintahan Desa Kementerian Dalam Negeri Republik Indonesia yaitu sebanyak 130 responden. Metode analisis yang digunakan adalah Structural Equation Modeling (SEM) dengan menggunakan AMOS versi 23. Hasil penelitian ini adalah terdapat pengaruh Training Satisfaction terhadap Work Engagement, terdapat pengaruh Supervisor Support terhadap Work Engagement, terdapat pengaruh Work Engagement terhadap Turnover Intention. Hasil selanjutnya, ditemukan bahwa terdapat pengaruh Training Satisfaction terhadap Turnover Intention yang dimediasi oleh Work Engagement, dan terdapat pengaruh Supervisor Support terhadap Turnover Intention yang dimediasi oleh Work Engagement. Dari hasil penelitian ini disarankan kepada Kepala Subbag Kepegawaian dan Kepala Bidang untuk menjaga tingkat Training Satisfaction yang secara efektif berpengaruh pada kualitas performa pegawai serta dapat memberikan manfaat bagi kemajuan perusahaan, mempertahankan sikap positif dalam hal memberikan dukungan kepada pegawai sehingga mereka merasa terikat secara emosional, meningkatkan partisipasi pegawai dalam menyelesaikan tugas untuk menciptakan Work Engagement, dan mencegah terjadinya Turnover Intention yang tinggi agar kinerja organisasi dan produktivitas perusahaan tetap efektif.
\end{abstract}

Kata kunci: Training Satisfaction, Supervisor Support, Turnover Intentions, dan Work Engagement.

\section{ABSTRACT}

The objective of the empirical study is to analyse the impact of Training Satisfaction, Supervisor Support on Turnover Intentions mediated by Work Engagement. This research uses by distributing questionnaires and the sampling method using purposive sampling involving 130 employees of Direktorat Jenderal Bina Pemerintahan Desa Kementerian Dalam Negeri Republik Indonesia. The analysis tools in this research is Structural 


\section{e-ISSN: 2443-0064}

Equation Modeling (SEM) tools with AMOS 23.0 version. The result of this study is that there is an influence of Training Satisfaction on Work Engagement, there is an influence of Supervisor Support on Work Engagement, there is an influence of Work Engagement on Turnover Intention. Further results, it was found that there was an influence of Training Satisfaction on Turnover Intention mediated by Work Engagement, and there was an influence of Supervisor Support on Turnover Intention mediated by Work Engagement. From the results of this study, it is recommended for Kepala Subbag Kepegawaian dan Kepala Bidang to maintain the level of Training Satisfaction which effectively impacts the quality of employee performance and can provide benefits for the progress of the company, maintain a positive attitude in terms of providing support to employees so that they feel emotionally attached, increase employee participation in completing tasks to create Work Engagement, and prevent the occurrence of high Turnover Intention so that organizational performance and company productivity remain effective.

Keyword: Training Satisfaction, Supervisor Support, Turnover Intentions, and Work Engagement.

\section{PENDAHULUAN}

Suatu organisasi bisnis di bidang jasa maupun produk berkeinginan untuk dapat mencapai tujuan agar terus berkembang. Mereka perlu mengatur dan mengelola sumber daya yang berharga, dimana salah satu aset pentingnya adalah karyawan (Ferdian, Ary 2020). Berdasarkan survei laporan data yang dilakukan di Amerika Serikat, pada tahun 2020 tingkat turnover karyawan untuk semua industri adalah 20\% sedangkan pada tahun 2019 sebesar 27,9\%. Walaupun terjadi penurunan, tingkat Turnover Intention masih menjadi risiko bagi organisasi. Turnover Intention menjadi salah satu perhatian khusus suatu organisasi karena mengarah pada produktivitas, kualitas produk dan layanan, serta profitabilitas suatu organisasi (Belete, AK 2017). Fenomena ini yang membuat berbagai organisasi berusaha untuk mengendalikan tingkat Turnover Intention karyawan.

Kementerian Dalam Negeri Republik Indonesia (Kemendagri RI) merupakan Kementerian yang membidangi permalasahan yang ada di dalam negeri. Kementerian Dalam Negeri itu sendiri, berada dibawah naungan Presiden dan bertanggung jawab kepada Presiden (Kemendagri.go.id). Selanjutnya Kementerian Dalan Negeri di atur pada Peraturan Presiden Republik Indonesia Nomor 11 Tahun 2015 Tentang Kementerian Dalam Negeri, kemudian berdasarkan Peraturan Menteri Dalam Negeri Republik Indonesia Nomor 43 Tahun 2015 Tentang Organisasi dan Tata Kerja Kementerian Dalam Negeri, Direktorat Jenderal Bina Pemerintahan Desa yang sebelumnya bernama Direktorat Jenderal Pemberdayaan Masyarakat dan Desa adalah unsur pelaksana Kementerian Dalam Negeri di Bidang Pembinaan Pemerintahan Desa. Direktorat Jenderal Bina Pemerintahan Desa yang berada di bawah dan bertanggung jawab kepada Menteri Dalam Negeri.

Berkaitan dengan pentingnya menjaga tingkat Turnover Intention di Direktorat Jenderal Bina Pemerintahan Desa, pegawai yang keluar pada satu sub bagian tertentu 


\section{e-ISSN: 2443-0064}

adalah pegawai yang belum cukup berpengalaman, terdapat organisasi yang belum bisa mengeluarkan dana untuk pengembangan pegawai, pegawai menduduki posisi yang tidak penting (marginal), dan pegawai yang merasa tidak puas dengan pekerjaannya. Melihat begitu berartinya pegawai bagi keberlangsungan organisasi, maka organisasi harus mempertahankan pegawai dengan berbagai strategi. Untuk mencegah meningkatnya Turnover Intention, perlu dilaksanakan strategi investasi yang sifatnya tidak langsung. Strategi itu meliputi stabilitas pekerjaan, pelatihan, dan keadilan prosedural. Selanjutnya, strategi ini juga memastikan adanya kesempatan untuk promosi jabatan, adanya program mentoring dari pegawai senior pada pegawai junior, serta adanya saluran komunikasi yang lancar (Mahmudah, 2016).

Menurut Yucel et al (2021) turnover, yang berarti pemutusan hubungan kerja antara organisasi dan orang tersebut yang terjadi dalam dua cara yaitu, pergantian sukarela atau pergantian tidak sukarela. Turnover Intention sebagai keinginan yang disengaja dan disengaja untuk meninggalkan organisasi. Dengan memeriksa pegawai yang akan Turnover Intention, organisasi dapat mengukur efektivitas kebijakan manajemen sumber daya manusia, mengidentifikasi karyawan yang berpikir untuk meninggalkan pekerjaan, dan mengurangi biaya perilaku turnover. Namun, jika mana pergantian pegawai tidak dapat dicegah, biaya organisasi (biaya pergantian, biaya penggantian personel dan biaya pelatihan personel) dapat meningkat, fungsi organisasi dapat memburuk, dan anggota organisasi yang tersisa mungkin mengalami depresi. Tingkat Turnover Intention dapat dilihat oleh adanya praktik HRM dan sumber daya pekerjaan potensial yang mendorong tekad dan upaya kerja pegawai (Memon et al., 2020).

Salah satu praktik HRM yaitu Training Satisfaction penting untuk meningkatkan hasil pegawai dalam hal kepuasan kerja, kepuasan pengguna, komitmen organisasi, serta keuangan (Memon et al., 2020). Training Satisfaction dapat diperoleh pada setiap organisasi yang menetapkan proses pelatihan yang sistematis dalam rangka meningkatkan keterampilan dan pengetahuan yang dibutuhkan untuk pekerjaan pegawai (Rahman, Susanti, dan Rojuaniah, 2021). Menurut Pattnaik dan Panda (2020) Supervisor Support yang merupakan sumber daya pekerjaan dapat membantu karyawan dalam mengatasi masalah dan membuat pegawai merasa bahwa atasan mereka mendukung serta peduli terhadap kesejahteraan. Dengan demikian, mereka akan merasa terikat pada organisasi dan berkewajiban untuk "membalas kebaikan" dengan tetap berada di organisasi.

Pentingnya Work Engagement mengarah pada pemenuhan pribadi, pengalaman terkait pekerjaan, kesehatan yang baik, dan keadaan pikiran untuk menghasilkan upaya kerja progresif (Memon et al., 2021). Work Engagement sebagai proses yang mendukung tingkat Training Satisfaction untuk mempertahankan motivasi karyawan yang kemudian dapat mencapai hasil kerja positif ditandai dengan rendahnya Turnover Intention pegawai (Memon, Salleh, dan Baharom, 2016). Menurut Sawasdee, Saengchai, dan Jermsittiparsert 
(2020), tingginya tingkat Work Engagement ditandai dengan adanya peran Supervisor Support untuk meningkatkan persepsi positif pegawai. Persepsi pegawai tentang suatu organisasi sangat penting karena menggambarkan perbandingan yang sebenarnya dari apa yang disediakan oleh organisasi dan apa yang diterima oleh karyawan, sehingga berdampak pada hasil dari Work Engagement yang cenderung memiliki peran terhadap tinggi rendahnya Turnover Intention pegawai (Zhang et al., 2018).

\section{LANDASAN TEORI DAN PENGEMBANGAN HIPOTESIS}

\section{Training Satisfaction}

Training Satisfaction mengacu pada tingkat seseorang menyukai atau tidak menyukai serangkaian kegiatan terencana yang diorganisasikan untuk mengembangkan pengetahuan, keterampilan, dan sikap yang secara efektif membantu dalam melakukan tugas atau pekerjaan tertentu. Training yang berkualitas tidak hanya meningkatkan pegawai kapasitas untuk memenuhi tuntutan pekerjaan tetapi menyediakan mekanisme untuk pertumbuhan pegawai. Training Satisfaction berguna untuk menghasilkan pegawai melalui sumber daya yang akan membuat mereka merasa terlibat dalam peran setiap pegawai (Memon et al., 2020).

Menurut Jaworski et al., (2018), Training Satisfaction sangat berpengaruh dalam proses kerja, mendorong fungsi lain, dan mengembangkan kreativitas untuk melaksanakan pekerjaan dengan lebih efektif (Rahman, Susanti, dan Rojuaniah, 2021). Tingkat Training Satisfaction rendah atau niat pegawai dalam bekerja menurun, maka organisasi harus mengadopsi metode pelatihan yang berdampak pada Training Satisfaction sebagai upaya untuk memaksimalkan peningkatan komitmen pegawai untuk bekerja.

\section{Supervisor Support}

Supervisor Support menjelaskan sejauh mana supervisor atau manajer mendukung dan memperkuat penggunaan pembelajaran di tempat kerja (Pattnaik dan Panda, 2020). Supervisor Support mengacu pada pendapat dan keyakinan umum bahwa supervisor peduli pada kesejahteraan dan menghargai kontribusi dalam organisasi yang telah mereka lakukan (Sawasdee, Saengchai, dan Jermsittiparsert, 2020).

Menurut Suan dan Nasrudin (2016), Supervisor Support di tempat kerja dilihat melalui tiga bentuk, pertama dukungan emosional yang mencakup empati, penerimaan, serta perhatian. Kedua dukungan informatif, seperti memberikan umpan balik atau bimbingan dalam pekerjaan yang dilakukan. Ketiga dukungan material, seperti menyiapkan anggaran, bantuan sosial, sumber daya, dan bantuan yang berhubungan dengan pekerjaan untuk meningkatkan motivasi, kinerja, dan efektivitas para bawahan. 


\section{Work Engagement}

Work Engagement adalah ketika pegawai siap untuk mempekerjakan dan mengekspresikan diri yang mereka sukai ke dalam pekerjaan secara fisik, kognitif, dan emosional (Khan et al., 2021). Kemudian, menurut Furuoka dan Idris (2020), Work Engagement didefinisikan sebagai konsep kritis yang mencerminkan partisipasi pegawai dalam menyelesaikan tugas yang digambarkan sebagai antusiasme yang berorientasi pada pekerjaan, kekuatan, dorongan, komitmen, fokus yang kuat dan pikiran yang positif.

Dimensi pada Work Engagement menurut Memon et al., (2020), merupakan indikator motivasi intrinsik di tempat kerja dan mengacu pada keadaan pikiran yang positif dan memuaskan. pegawai yang terlibat telah memperoleh tingkat absorption, vigor, dan dedication yang tinggi.

1. Absorption ditandai dengan sepenuhnya terlibat dalam organisasi dan memiliki perasaan bahagia dalam pekerjaan seseorang.

2. Vigor ditandai dengan tinggi rendahnya energi serta ketahanan mental yang tinggi saat melaukan pekerjaan.

3. Dedication ditandai oleh kepetningan, antusiasme, inspirasi, kebanggaan, serta tantangan di tempat kerja.

Peran Work Engagement sebagai motivasi emosional positif dan keadaan mental universal yang menunjukkan perilaku pekerja dan hasil terkait kinerja (Nakra dan Arora, 2021). Wirawan, Jufri, dan Saman (2020) juga menyebutkan bahwa Work Engagement didorong oleh keberadaan sumber daya pekerjaan (misalnya supervisor) dan sumber daya pribadi (misalnya self-efficacy). Sumber daya pekerjaan bersumber dari organisasi seperti dukungan pengawasan dan perilaku pemimpin yang positif, sedangkan sumber daya pribadi berasal dari keadaan psikologis individu seperti kemanjuran dan optimisme.

\section{Turnover Intention}

Turnover intention merupakan pola ketika pegawai memutuskan untuk meninggalkan organisasi, yang dianggap sebagai keinginan pribadi untuk meninggalkan organisasi (Saaed, 2020). Kemudian, Lin, Tsai, dan Mahatma (2017) mendefinisikan Turnover intention sebagai keinginan yang dilakukan dengan sengaja dan dalam keadaan sadar untuk bisa meninggalkan organisasi secepatnya.

Turnover intention menjadi perhatian khusus bagi para pemimpin di seluruh organisasi bisnis, karena dapat merusak etika di tempat kerja. Oleh karena itu, penting bagi manajemen untuk memahami hubungan antara Turnover Intention, determinannya, atau moderator secara mendalam. Tingginya tingkat Turnover Intention pegawai tidak hanya mengarah pada biaya keuangan langsung, tetapi juga menghasilkan kinerja organisasi yang 
lebih rendah, produktivitas rendah, moral rendah dan gangguan layanan, yang mengakibatkan ketidakpuasan pegawai (Lu et al., 2016).

\section{Pengembangan Hipotesis}

Hasil penelitian dari Memon et al., (2021) yang melakukan penelitian pada 422 responden di International Petroleum Technology Conference bertempat di Kuala Lumpur, dan alumni department O\&G, bahwa terdapat pengaruh signifikan Training Satisfaction terhadap Work Engagement. Kemudian, penelitian yang dilakukan oleh Rahman, Susanti, dan Rojuaniah (2021), dijelaskan bahwa Training Satisfaction memiliki pengaruh terhadap Work Engagement yang dilakukan pada 288 pegawai di Jakarta, Indonesia. Selanjutnya, telah dilakukan penelitian pada 409 pegawai profesional yang bekerja di Oil dan Gas di Malaysia, ditemukan bahwa Training Satisfaction berpengaruh terhadap Work Engagement (Memon, Salleh, dan Baharom, 2016). Berdasarkan hasil penelitian sebelumnya, maka hipotesis dapat dinyatakan sebagai berikut :

\section{H1 : Terdapat pengaruh Training Satisfaction terhadap Work Engagement.}

Dalam penelitian yang dilakukan oleh Pattnaik dan Panda (2020) bahwa terdapat pengaruh Supervisor Support terhadap Work Engagement yang melakukan penelitian pada 386 pegawai pusat panggilan yang berlokasi di berbagai kota di negara India yang mencakup tingkat yang berbeda. Selanjutnya, hasil penelitian Suan dan Nasrudin (2016), menemukan bahwa Supervisor Support memiliki pengaruh terhadap Work Engagement pada 438 pegawai yang berhubungan dengan pelanggan di hotel kelas atas Malaysia. Kemudian, telah dilakukan penelitian oleh Sawasdee, Saengchai, dan Jermsittiparsert (2020) pada 355 responden di 6 perusahaan farmasi di Thailand, bahwa adanya pengaruh signifikan Supervisor Support terhadap Work Engagement. Berdasarkan hasil penelitian sebelumnya, maka hipotesis dapat dinyatakan sebagai berikut :

\section{H2 : Terdapat pengaruh Supervisor Support terhadap Work Engagement.}

Berdasarkan penelitian yang dilakukan oleh Memon et al., (2021) yang melakukan penelitian pada 422 responden di International Petroleum Technology Conference bertempat di Kuala Lumpur, dan alumni department O\&G, bahwa terdapat pengaruh Work Engagement terhadap Turnover Intention. Kemudian, telah dilakukan penelitian oleh Kim dan Hyun (2017) yang melakukan penelitian pada 571 responden di organisasi Korea bahwa Work Engagement memiliki pengaruh terhadap Turnover Intention. Selain itu, Zhang et al., (2018), menemukan bahwa adanya pengaruh Work Engagement terhadap Turnover Intention yang melakukan penelitian pada 2426 pegawai kesehatan kotapraja di Provinsi Sichuan, China. Sehingga berdasarkan penelitian tersebut, maka hipotesis dapat dinyatakan sebagai berikut :

H3 : Terdapat pengaruh Work Engagement terhadap Turnover Intention.

Berdasarkan penelitian yang dilakukan oleh Memon et al., (2021) yang melakukan penelitian pada 422 responden di International Petroleum Technology Conference 
e-ISSN: 2443-0064

bertempat di Kuala Lumpur, dan alumni department O\&G, bahwa Work Engagement adalah sebagai mediator yang signifikan dimana Training Satisfaction mempengaruhi Turnover Intention. Kemudian, telah dilakukan penelitian kembali oleh Memon, Salleh, dan Baharom (2016) pada 409 pegawai profesional yang bekerja di Oil dan Gas di Malaysia, ditemukan bahwa Work Engagement memediasi pengaruh Training Satisfaction terhadap Turnover Intention. Berdasarkan hasil penelitian tersebut, maka hipotesis dinyatakan sebagai berikut :

H4 : Terdapat pengaruh Training Satisfaction terhadap Turnover Intention yang dimediasi oleh Work Engagement.

Dalam penelitian yang dilakukan oleh Pattnaik dan Panda (2020) yang melakukan penelitian pada 386 pegawai pusat panggilan yang berlokasi di berbagai kota di negara India, menyebutkan bahwa pengaruh Supervisor Support terhadap Turnover Intention dimediasi oleh adanya faktor Work Engagement yang ada pada organisasi. Berdasarkan penelitian sebelumnya, maka hipotesis dinyatakan sebagai berikut :

H5 : Terdapat pengaruh Supervisor Support terhadap Turnover Intention yang dimediasi oleh Work Engagement.

Berdasarkan teori-teori yang berkaitan dengan tujuan penelitian yang akan dicapai, maka model dalam penelitian ini digambarkan ke dalam Rerangka Konseptual sebagai berikut :

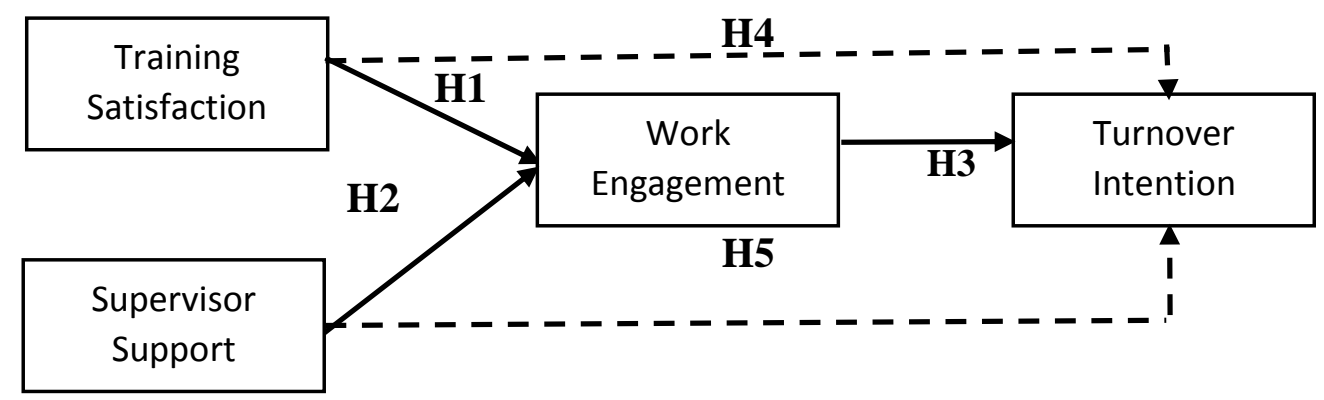

\section{METODE PENELITIAN}

\section{Rancangan Penelitian}

Penelitian ini merupakan gabungan dari beberapa penelitian yang dilakukan oleh Memon et al., (2021) yang berjudul "Satisfaction matters: the relationships between HRM practices, work engagement and turnover intention" serta penelitian yang dilakukan oleh Pattnaik dan Panda (2020) dengan judul "Supervisor support, work engagement and turnover intentions: evidence from Indian call centres” penelitian ini bertujuan untuk 


\section{e-ISSN: 2443-0064}

menganalisis pengaruh Training Satisfaction, Supervisor Support terhadap Turnover Intention yang dimediasi oleh Work Engagement.

Jenis penelitian yang dilakukan adalah metode kuantitatif dengan menggunakan survey research studi di Direktorat Jenderal Bina Pemerintahan Desa Kementerian Dalam Negeri Republik Indonesia. Metode penelitian yang digunakan adalah metode hypothesis testing. Unit penelitian ini adalah individu, yaitu pegawai yang bekerja di Direktorat Jenderal Bina Pemerintahan Desa Kementerian Dalam Negeri Republik Indonesia. Pengambilan data dilakukan dengan cara cross sectional karena peneliti dapat langsung mengolah data berupa jawaban kuesioner yang hanya dilakukan dalam satu waktu mulai pada 17 Juli 2021 hingga 21 Juli 2021. Penelitian ini dilakukan dengan penyebaran kuesioner.

\section{Variabel dan Pengukuran}

Penelitian ini terdiri dari empat (4) variabel yaitu, tiga (3) variabel bebas (independent variable), satu (1) variabel perantara (intervening variable), dan satu (1) variabel terikat (dependent variable) penelitian atas jawaban responden dilakukan berdasarkan Likert dari 1 sampai 5: nilai 1 "sangat tidak setuju", nilai 2 "tidak setuju", nilai 3 "cukup setuju", nilai 4 "setuju", nilai 5 "sangat setuju".

\section{Teknik Pengumpulan Data}

Teknik pengumpulan data dalam penelitian ini menggunakan Data Primer. Penelitian dilakukan untuk mendapatkan data primer yang mengacu pada informasi yang diperoleh langsung ke lapangan yang menjadi objek penelitian berupa data yang akan diolah menjadi informasi yang diperlukan (Sekaran dan Bougie, 2017). Penyebaran kuesioner dilakukan kepada pegawai Direktorat Jenderal Bina Pemerintahan Desa Kementerian Dalam Negeri Republik Indonesia sebanyak 130 responden.

\section{Sampel Penelitian}

Dalam penelitian ini sampel yang diambil adalah pegawai Direktorat Jenderal Bina Pemerintahan Desa Kementerian Dalam Negeri Republik Indonesia difokuskan pada Bagian Kepegawaian yang merupakan salah satu sub bagian dari Bidang Umum dibawah Sekretariat Ditjen Bina Pemdes, menggunakan non probabilitas sampling dengan metode pengambilan sampel dengan teknik purposive sampling yaitu penarikan sampel melalui bebrapa kriteria yang sudah ditentukan oleh peneliti (Sekaran dan Bougie, 2017). Penentuan jumlah sampel menurut Hair et al., (2010) disarankan ukuran sampel yang sesuai antara 100-200 responden agar dapat digunakan dengan Structural Equation Modeling (SEM). Jumlah sampel minimum jika jika menggunakan SEM menurut Hair et al., (2010) adalah: (Jumlah Indikator + Jumlah Variabel Laten) x (5 sampai 10 kali). Dalam penelitian ini, jumlah sampel yang digunakan adalah: $(22+4) \times 5=130$ pegawai 
yang bekerja di Direktorat Jenderal Bina Pemerintahan Desa Kementerian Dalam Negeri Republik Indonesia yang dilihat dari karakteristik responden yaitu (minimal berusia 20 tahun), pendidikan terakhir, dan waktu masa kerja (minimal 1 tahun). Alasan memilih menggunakan kriteria tersebut karena peneliti ingin mencari tahu apakah pegawai tersebut memiliki tingkat Turnover Intention yang tinggi atau rendah.

\section{Analisis Data}

\section{Uji Instrumen Peneliti}

Pengumpulan data dilakukan dengan menggunakan kuesioner, maka untuk menghindari adanya kesalahan dilakukan uji instrumen agar mengetahui tujuan dari peneliti (valid) dan tingkat konsisten apabila pernyataan tersebut dijawab dalam waktu yang berbeda (reliable).

\section{Uji Validitas}

Uji validitas digunakan untuk mengukur valid atau tidaknya suatu kuesioner (Sekaran dan Bougie, 2017). Pengujian validitas ini dilakukan dengan mencari korelasi dari tiap indikator dengan etode pengujian yang digunakan adalah Structural Equation Modeling (SEM) yang diolah dengan software AMOS versi 23.

Kriteria uji validitas dengan melihat nilai factor loading apakah lebih besar dari 0,05 atau lebih kecil dari 0,05 .

- Jika factor loading >0,05 valid

- Jika factor loading <0,05 tidak valid

\section{Uji Reliabilitas}

Uji reliabilitas untuk mengetahui tingkat konsistensi apabila dilakukan pengukuran dua kali atau lebih (Sugiyono, 2010). Menurut Sekaran (2006) dasar pengambilan keputusan uji reabilitas ini adalah sebagai berikut :

a. Jika koefisien Cronbach's Alpha $\geq 0,6$ maka Cronbach's Alpha Acceptable (construct reliable).

b. Jika Cronbach's Alpha < 0,6 maka Cronbach's Alpha Poor Acceptable (construct unreliable).

Nilai Cronbach's Alpha adalah tingkat keandalan (reliability) dari masing-masing angket variabel.

Pada Tabel 1 terlihat hasil uji instrumen yaitu uji validitas dan uji reliabilitas terdapat 21 item pernyataan yang valid dan 4 variabel dikatakan reliabel, sehingga dapat dilanjutkan dalam penelitian.

Tabel 1. Uji Validitas, Uji Reliabilitas, dan Statistik Deskriptif

\begin{tabular}{lllcll}
\hline Variabel dan Indikator & n & Mean & $\begin{array}{c}\text { Nilai } \\
\text { Factor }\end{array}$ & $\begin{array}{c}\text { Nilai } \\
\text { Cronbach's }\end{array}$ & Keputusan \\
\hline
\end{tabular}




\begin{tabular}{|c|c|c|c|c|c|}
\hline & & & $\begin{array}{c}\text { Loading } \\
\quad \text { (Ujii } \\
\text { Validitas) }\end{array}$ & $\begin{array}{c}\text { Alpha } \\
\text { (Uji } \\
\text { Reliabilitas) }\end{array}$ & \\
\hline Training Satisfaction & 130 & 4,05 & & 0,84 & Reliabel \\
\hline $\begin{array}{l}\text { 1. Secara keseluruhan, pelatihan } \\
\text { di tempat kerja yang saya } \\
\text { terima berlaku untuk pekerjaan } \\
\text { saya }\end{array}$ & 130 & 4,22 & 0,906 & & Valid \\
\hline $\begin{array}{l}\text { 2. Secara keseluruhan, pelatihan } \\
\text { yang saya terima di tempat } \\
\text { kerja memenuhi kebutuhan saya }\end{array}$ & 130 & 4,14 & 0,856 & & Valid \\
\hline $\begin{array}{l}\text { 3. Secara keseluruhan, saya } \\
\text { puas dengan jumlah pelatihan } \\
\text { yang saya terima di tempat } \\
\text { kerja }\end{array}$ & 130 & 3,78 & 0,565 & & Valid \\
\hline $\begin{array}{l}\text { 4. Saya biasanya dapat } \\
\text { menggunakan apa yang saya } \\
\text { pelajari di tempat kerja }\end{array}$ & 130 & 4,05 & 0,710 & & Valid \\
\hline Supervisor Support & 130 & 3,59 & & 0,67 & Reliabel \\
\hline $\begin{array}{l}\text { 5. Saya menemukan atasan saya } \\
\text { sangat membantu dalam } \\
\text { melakukan tugas dan pekerjaan } \\
\text { saya }\end{array}$ & 130 & 3,96 & 0,714 & & Valid \\
\hline $\begin{array}{l}\text { 6. Saat melakukan tugas dan } \\
\text { pekerjaan, saya sangat } \\
\text { bergantung pada atasan saya }\end{array}$ & 130 & 2,99 & 0,318 & & Not Valid \\
\hline $\begin{array}{l}\text { 7. Atasan saya memberi saya } \\
\text { informasi dan saran penting } \\
\text { terkait pekerjaan yang membuat } \\
\text { pekerjaan saya lebih mudah }\end{array}$ & 130 & 3,83 & 0,900 & & Valid \\
\hline $\begin{array}{l}\text { 8. Saya dapat mengandalkan } \\
\text { supervisor } \\
\text { melakukan "hal yang benar" } \\
\text { saat bekerja }\end{array}$ & 130 & 3,59 & 0,583 & & Valid \\
\hline Work Engagement & 130 & 4,05 & & $\mathbf{0 , 9 3}$ & Reliabel \\
\hline $\begin{array}{l}\text { 9. Ketika saya bangun di pagi } \\
\text { hari, saya merasa ingin pergi } \\
\text { bekerja }\end{array}$ & 130 & 3,93 & 0,800 & & Valid \\
\hline
\end{tabular}




\section{e-ISSN: 2443-0064}

10. Di tempat kerja, saya merasa penuh dengan energi

$130 \quad 4,02 \quad 0,828$

Valid

11. Di pekerjaan saya, saya merasa kuat dan bersemangat

$130 \quad 4,03 \quad 0,900 \quad$ Valid

\begin{tabular}{llllll}
\hline $12 . \quad$ Pekerjaan & saya & 130 & 4,03 & 0,881 & Valid \\
menginspirasi saya & & &
\end{tabular}

menginspirasi saya

$\begin{array}{lllllll}\text { 13. Saya antusias dengan } & 130 & 4,09 & 0,894 & \text { Valid }\end{array}$
pekerjaan saya

\begin{tabular}{|c|c|c|c|c|}
\hline $\begin{array}{l}\text { 14. Saya bangga dengan } \\
\text { pekerjaan yang saya lakukan }\end{array}$ & 130 & 4,27 & 0,718 & Valid \\
\hline $\begin{array}{l}\text { 15. Saya terbawa suasana ketika } \\
\text { saya bekerja }\end{array}$ & 130 & 3,97 & 0,525 & Valid \\
\hline $\begin{array}{l}\text { 16. Saya merasa nyaman dalam } \\
\text { pekerjaan saya }\end{array}$ & 130 & 4,04 & 0,722 & Valid \\
\hline $\begin{array}{l}\text { 17. Saya merasa senang ketika } \\
\text { saya bekerja secara intens }\end{array}$ & 130 & 4,08 & 0,763 & Valid \\
\hline Turnover Intention & 130 & 2,77 & & Reliabel \\
\hline $\begin{array}{lr}18 . \quad \text { Saya } & \text { serius } \\
\text { mempertimbangkan untuk } \\
\text { meninggalkan pekerjaan saya } \\
\text { saat ini untuk bekerja di } \\
\text { unit/organisasi/tempat lain }\end{array}$ & 130 & 3,17 & 0,580 & Valid \\
\hline $\begin{array}{l}\text { 19. Saya terkadang merasa } \\
\text { harus berhenti dari pekerjaan } \\
\text { saya di tempat kerja saya saat } \\
\text { ini }\end{array}$ & 130 & 2,73 & 0,745 & Valid \\
\hline $\begin{array}{l}\text { 20. Saya mungkin akan mencari } \\
\text { pekerjaan baru di tahun depan }\end{array}$ & 130 & 2,53 & 0,873 & Valid \\
\hline $\begin{array}{l}\text { 21. Dalam } 6 \text { bulan ke depan, } \\
\text { saya akan menilai kemungkinan } \\
\text { meninggalkan pekerjaan saya } \\
\text { saat ini adalah tinggi }\end{array}$ & 130 & 2,41 & 0,878 & Valid \\
\hline $\begin{array}{l}\text { 22. Saya akan keluar dari } \\
\text { unit/organisasi/tempat ini jika } \\
\text { kondisi yang diberikan menjadi } \\
\text { sedikit lebih buruk dari } \\
\text { sekarang }\end{array}$ & 130 & 3,00 & 0,704 & Valid \\
\hline
\end{tabular}




\section{e-ISSN: 2443-0064}

Hasil pengolahan data yang ada Tabel 1 di atas, bahwa terdapat nilai statistik deskriptif untuk variabel Training Satisfaction, Supervisor Support, Work Engagement, Turnover Intention yang dapat dilihat secara keseluruhan pada setiap item pernyataan. Pada variabel Training Satisfaction, diketahui bahwa nilai rata-rata adalah 4,05. Hal ini menunjukkan bahwa responden membenarkan jika memiliki perasaan puas terhadap kegiatan training yang dapat mengembangkan pengetahuan, keterampilan, dan sikap dalam melakukan tugas atau pekerjaan secara efektif. Selanjutnya, berdasarkan dari Tabel 1, variabel Supervisor Support memiliki nilai rata-rata 3,59 yang berarti responden merasa sependapat dengan adanya dukungan dari Supervisor yang dapat membantu pekerjaan, memberikan informasi, serta memberikan saran sehingga lebih mudah dalam menjalankan pekerjaan secara maksimal. Kemudian Variabel Work Engagement diketahui bahwa nilai rata-rata adalah 4,05. Hal ini dapat diartikan bahwa pegawai menunjukkan adanya keterlibatan dalam bekerja di instansinya. Pegawai menunjukkan energi yang kuat, semangat, antusias, dan memiliki rasa nyaman dalam bekerja. Sehingga pekerjaan menjadi sebuah inspirasi dan kebanggaan. Selanjutnya, perlu diketahui bahwa pada variabel Turnover Intention memiliki nilai rata-rata 2,77. Hal ini menunjukkan bahwa responden cukup sependapat dengan adanya keinginan untuk pindah kerja, dilihat dari sikap pegawai dalam mempertimbangkan untuk meninggalkan pekerjaan di tempat saat ini mereka bekerja.

Dalam penelitian ini, dilakukan uji kesesuaian model untuk melihat model tersebut menggambarkan seluruh sebab akibat. Uji kesesuaian model atau Goodness of Fit memiliki tujuan untuk menguji model yang diusulkan memiliki kesesuaian (fit) dengan data sampel maupun tidak. Pengujian ini dilakukan dengan beberapa kriteria pengukuran (Hair, et al., 2010) yaitu menguji nilai Absolute Fit Measures, Incremental Fit Measures, dan Parsimonious Fit Measures. Berdasarkan hal tersebut, pengukuran Goodness of Fit dalam penelitian ini dijelaskan pada Tabel 2.

Tabel 2. Uji Goodness of Fit

\begin{tabular}{ccccc}
\hline \multirow{2}{*}{ Jenis Pengukuran } & Pengukuran & Nilai & $\begin{array}{c}\text { Batas } \\
\text { penerimaan } \\
\text { yang disarankan } \\
\text { Hair } \text { et al., 2010 }\end{array}$ & Kesimpulan \\
\hline \multirow{2}{*}{ Absolute Fit Measures } & & \multicolumn{2}{c}{$\begin{array}{c}\text { Small Chi- } \\
\text { Square }\end{array}$} & $\begin{array}{c}\text { Goodness of } \\
\text { Fit }\end{array}$ \\
\cline { 2 - 5 } & P-Value & 0,000 & $\geq 0,05$ & Marginal Fit \\
\cline { 2 - 5 } & RMSEA & 0,08 & $\leq 0,08$ & $\begin{array}{c}\text { Goodness of } \\
\text { Fit }\end{array}$ \\
\cline { 2 - 6 } & GFI & 0,78 & $\geq 0,90$ & Marginal Fit \\
\hline Incremental Fit Measures & NFI & 0,802 & $\geq 0,90$ & Marginal Fit \\
\hline
\end{tabular}




\begin{tabular}{ccccc}
\hline & TLI & 0,88 & $\geq 0,90$ & Marginal Fit \\
\cline { 2 - 5 } & RFI & 0,774 & $\geq 0,90$ & Marginal Fit \\
\cline { 2 - 5 } & CFI & 0,892 & $\geq 0,90$ & Marginal Fit \\
\cline { 2 - 5 } Parsimonius Fit Measures & AGFI & 0,73 & $\geq 0,90$ & Marginal Fit \\
\hline & CMIN/DF & 1,935 & $\begin{array}{c}\text { Batas bawah : 1,0 } \\
\text { Batas atas : 5,0 }\end{array}$ & $\begin{array}{c}\text { Goodness of } \\
\text { Fit }\end{array}$ \\
\hline
\end{tabular}

Dari tabel hasil pengujian Goodness of Fit diketahui bahwa seluruh model yang digunakan dalam penelitian ini masuk dalam kriteria dari beberapa indikator kesesuaian model.

\section{HASIL ANALISIS DAN PEMBAHASAN}

\section{Karakteristik Responden}

Penelitian ini melibatkan obyek penelitian sebanyak 130 responden melalui penelitian lapangan secara langsung berupa kuesioner individual dan didistribusikan pada pegawai Direktorat Jenderal Bina Pemerintahan Desa Kementerian Dalam Negeri Republik Indonesia di wilayah Provinsi DKI Jakarta. Tabel 3 di bawah ini menunjukkan analisis deskriptif responden.

Tabel 3. Deskriptif Responden

\begin{tabular}{lcc}
\hline \multicolumn{1}{c}{ Category } & Frequency & Precentage \\
\hline Jenis Kelamin & & \\
\hline Perempuan & 65 & $50 \%$ \\
\hline Laki-Laki & 65 & $50 \%$ \\
\hline Total & $\mathbf{1 3 0}$ & $\mathbf{1 0 0 \%}$ \\
\hline Usia & \\
\hline $20-25$ & 18 & $13,8 \%$ \\
\hline $26-30$ & 34 & $26,2 \%$ \\
\hline $31-35$ & 18 & $13,8 \%$ \\
\hline Total & $\mathbf{1 3 0}$ & $\mathbf{1 0 0 \%}$ \\
\hline Pendidikan Terakhir & \\
\hline SMA/SMK & 10 & $7,7 \%$ \\
\hline D3 & 8 & $6,2 \%$ \\
\hline S1 & 77 & $59,2 \%$ \\
\hline Total & $\mathbf{1 3 0}$ & $\mathbf{1 0 0 \%}$ \\
\hline Masa Kerja & & \\
\hline$<1$ Tahun & 9 & $6,9 \%$ \\
\hline
\end{tabular}


e-ISSN: 2443-0064

\begin{tabular}{lcc}
\hline 1-5 Tahun & 39 & $30 \%$ \\
\hline 6-10 Tahun & 28 & $21,5 \%$ \\
\hline Total & $\mathbf{1 3 0}$ & $\mathbf{1 0 0 \%}$ \\
\hline
\end{tabular}

Analisis Data

Pengujian lima hipotesa dalam penelitian ini dilakukan dengan menggunakan metode SEM. Uji hipotesis dilakukan dengan cara membandingkan p-value 0,05 dengan ketentuan sebagai berikut:

a. Apabila p-value $\leq 0,05$ maka Ho ditolak Ha diterima

b. Apabila p-value $\geq 0,05$ maka Ho ditolak Ha diterima

Berikut ini akan dijelaskan pengujian hipotesis yang digunakan dalam penelitian ini:

Tabel 4. Pengujian Hipotesis

\begin{tabular}{lccc}
\hline \multicolumn{1}{c}{ Hipotesis } & Estimate & P-value & Keputusan \\
\hline $\begin{array}{l}\text { H1 : Terdapat pengaruh Training } \\
\text { Satisfaction terhadap Work Engagement. }\end{array}$ & 0,265 & 0,003 & Ha1 diterima \\
\hline $\begin{array}{l}\text { H2 : Terdapat pengaruh Supervisor Support } \\
\text { terhadap Work Engagement. }\end{array}$ & 0,482 & 0,000 & Ha2 diterima \\
\hline $\begin{array}{l}\text { H3 : Terdapat pengaruh Work Engagement } \\
\text { terhadap Turnover Intention. }\end{array}$ & $-0,265$ & 0,041 & Ha3 diterima \\
\hline $\begin{array}{l}\text { H4 : Terdapat pengaruh Training } \\
\text { Satisfaction terhadap Turnover Intention } \\
\text { yang dimediasi oleh Work Engagement. }\end{array}$ & $-0,068$ & 0,048 & Ha4 diterima \\
\hline $\begin{array}{l}\text { H5 : Terdapat pengaruh Supervisor Support } \\
\text { terhadap Turnover Intention yang dimediasi } \\
\text { oleh Work Engagement. }\end{array}$ & $-0,116$ & 0,040 & Ha5 diterima \\
\hline
\end{tabular}

Dari hasil pengujian hipotesis yang dilakukan, bahwa terdapat pengaruh Training Satisfaction terhadap Work Engagement dengan nilai P-value 0,003 $\leq 0,05$ sehingga H1 diterima. Hal ini sejalan dengan penelitian yang dilakukan oleh Memon et al., (2021) bahwa terdapat pengaruh Training Satisfaction terhadap Work Engagement yang dilakukan pada 422 responden di Kuala Lumpur. Training Satisfaction dilakukan untuk mengembangkan pribadi dan membantu pegawai dalam mencapai tujuan kerja mereka, sehingga dapat meningkatkan Work Engagement pegawai di tempat kerja. Seperti yang terjadi pada pegawai di Direktorat Jenderal Bina Pemerintahan Desa Kementerian Dalam Negeri Republik Indonesia, bahwa dengan adanya salah satu praktik HRM yaitu Training Satisfaction secara keseluruhan telah memberikan dampak positif dalam meningkatkan partisipatif pegawai untuk menyelesaikan pekerjaan yang berorientasi pada kekuatan, dorongan, komitmen, dan fokus pegawai. 


\section{e-ISSN: 2443-0064}

Pada hasil pengujian hipotesis, bahwa terdapat pengaruh Supervisor Support terhadap Work Engagement dengan nilai P-value 0,000 $\leq 0,05$ sehingga $\mathrm{H} 2$ diterima. Hal ini didukung dengan penelitian yang dilakukan oleh Pattnaik dan Panda (2020) bahwa terdapat pengaruh Supervisor Support terhadap Work Engagement yang dilakukan pada 386 responden di berbagai kota di negara India. Peran Supervisor Support sebagai bentuk tambahan kepercayaan yang dirasakan pegawai dalam melaksanakan tanggung jawab serta merasa bahwa dirinya ikut berperan dalam menyelesaikan suatu pekerjaan. Dengan demikian, akan menunjukkan sikap Work Engagement yang yang mencerminkan partisipasi pegawai efektif dan efisien. Pada Direktorat Jenderal Bina Pemerintahan Desa Kementerian Dalam Negeri Republik Indonesia, dengan adanya berbagai dukungan tersebut telah membantu pegawai dalam menciptakan motivasi secara emosional sehingga timbul perasaan dedikasi, antusiasme, inspirasi, kebanggaan, dan tantangan pekerjaan.

Selanjutnya dari hasil pengujian hipotesis, bahwa terdapat pengaruh Work Engagement terhadap Turnover Intention dengan nilai P-value 0,041 $\leq 0,05$ sehingga H3 diterima. Hal ini sesuai dengan penelitian yang dilakukan oleh Memon et al., (2021) yang melakukan penelitian pada 422 responden di International Petroleum Technology Conference bertempat di Kuala Lumpur, dan alumni department O\&G, bahwa terdapat pengaruh Work Engagement terhadap Turnover Intention. Pegawai yang terlibat dalam pekerjaan jauh lebih mungkin untuk mengalami emosi positif di tempat kerja dan dapat membangun sumber daya psikologis yang bertahan lama sehingga memicu kesejahteraan emosional. Selain itu, pegawai dengan tingkat Work Engagement yang tinggi, akan cenderung memiliki kesehatan yang baik dan mudah mengurangi stres di tempat kerja. Hal ini menunjukkan bahwa semakin tinggi tingkat Work Engagement pegawai maka pengaruh Turnover Intention akan semakin rendah (Agarwal et al., 2018).

Dari hasil pengujian hipotesis yang dilakukan, bahwa terdapat pengaruh Training Satisfaction terhadap Turnover Intention yang di mediasi oleh Work Engagement dengan nilai P-value 0,048 $\leq 0,05$ sehingga $\mathrm{H} 4$ diterima. Hasil ini didukung oleh penelitian yang dilakukan Memon, Salleh, dan Baharom (2016) pada 409 pegawai profesional yang bekerja di Oil dan Gas di Malaysia, ditemukan bahwa Work Engagement memediasi pengaruh Training Satisfaction terhadap Turnover Intention. Salah satu fungsi HRM yaitu Training Satisfaction, menunjukkan bahwa pelatihan yang cukup optimal bisa mendukung pekerjaan yang dapat meningkatkan keterlibatan melalui peran pekerjaan mereka, sehingga membuat pegawai merasa lebih semangat dan antusias dalam menyelesaikan pekerjaannya. Dengan demikian, pegawai cenderung tidak akan mencari peluang untuk berpindah dari instansi pemerintah. Oleh karena itu, perasaan positif pegawai tentang kegiatan pelatihan ini dapat menghasilkan hasil sikap dan perilaku yang positif, seperti misalnya rendahnya tingkat turnover pegawai. Seperti yang terjadi di Direktorat Jenderal Bina Pemerintahan Desa Kementerian Dalam Negeri Republik Indonesia, bahwa tingginya tingkat Work Engagement sebagai proses motivasi pegawai dalam menyelesaikan pekerjaan dapat 


\section{e-ISSN: 2443-0064}

menunjukkan peran mediasi antara pengaruh sumber daya pekerjaan yaitu Training Satisfaction dan mengurangi keinginan pegawai untuk pindah kerja.

Pada hasil H5 ditemukan nilai p-value $0,040 \leq 0,05$ yang berarti terdapat pengaruh Supervisor Support terhadap Turnover Intention yang dimediasi oleh Work Engagement. Hal ini sesuai dengan penelitian yang dilakukan oleh Pattnaik dan Panda (2020) yang melakukan penelitian pada 386 pegawai pusat panggilan yang berlokasi di berbagai kota di negara India, menyebutkan bahwa pengaruh Supervisor Support terhadap Turnover Intention dimediasi oleh adanya faktor Work Engagement yang ada pada organisasi. pegawai akan cenderung membalas organisasi melalui peningkatan Work Engagement akibat timbul sikap positif yaitu Supervisor Support. Dengan demikian, supervisor mendukung pegawai dan membantu mereka ketika menghadapi masalah yang berhubungan dengan pekerjaan, karena Work Engagement merupakan indikator motivasi intrinsik di tempat kerja dan mengacu pada keadaan pikiran yang positif. Selanjutnya, pegawai dengan Work Engagement yang tinggi dapat memberikan penghargaan atau sikap positif pula kepada organisasi dilihat dari berkurangnya tingkat niat mereka untuk meninggalkan organisasi. Pada Direktorat Jenderal Bina Pemerintahan Desa Kementerian Dalam Negeri Republik Indonesia, ketika pegawai diberikan dukungan oleh atasan, mereka merasa diberikan kepercayaan serta tanggung jawab untuk ikut berperan dalam membantu menyelesaikan pekerjaan, akibatnya pekerjaan yang dilakukan juga menghasilkan hasil kerja yang efektif dan efisien. Supervisor Support sebagai sumber daya pekerjaan menginduksi keterlibatan kerja di antara pegawai, yang pada gilirannya, menghasilkan penurunan tingkat niat untuk meninggalkan organisasi.

\section{PENUTUP}

\section{Simpulan}

Berdasarkan hasil penelitian, ditemukan bahwa pada variabel Training Satisfaction diketahui memiliki nilai rata-rata 4,05 yang menunjukkan bahwa pegawai membenarkan jika memiliki perasaan puas terhadap kegiatan training. Kemudian, Supervisor Support memiliki nilai rata-rata 3,59 yang berarti responden sependapat dengan adanya dukungan dari supervisor yang dapat meningkatkan motivasi mereka dalam menyelesaikan pekerjaan secara maksimal, selanjutnya Work Engagement dengan nilai rata-rata 4,05 yang berarti bahwa keterlibatan kerja pegawai merupakan salah satu indikator penting apakah organisasi berjalan dengan baik karena berpengaruh terhadap kinerja, pergantian niat, dan kepuasan kerja. Selain itu, Work Engagement menunjukkan tingkat energi yang tinggi, antusias, kebanggaan, serta merasa senang sampai terbawa suasana saat bekerja. Pada variabel Turnover Intention memiliki nilai rata-rata 2,77 yang menunjukkan bahwa pegawai cukup sependapat untuk mempertimbangkan keinginan untuk pindah kerja dan meninggalkan perusahaan. Hasil penelitian juga menunjukkan $\mathrm{H} 1$ diterima memiliki nilai 
p-value $0,003 \leq 0,05$ yang artinya Training Satisfaction berpengaruh positif pada Work Engagement, bahwa tingginya tingkat kepuasan pegawai dalam kegiatan training mampu menciptakan keterlibatan kerja mereka yang mendukung tercapainya efektivitas perusahaan. Selanjutnya, pada H2 diterima memiliki nilai p-value 0,000 $\leq 0,05$ yang berarti Supervisor Support berpengaruh positif terhadap Work Engagement, sehingga dapat disimpulkan bahwa tingginya dukungan supervisor mampu meningkatkan partisipasi pegawai dalam pekerjaan. Untuk hasil H3 diterima dengan nilai p-value $0,041 \leq 0,05$ yang berarti terdapat pengaruh Work Engagement terhadap Turnover Intention. Sehingga semakin pegawai terlibat dalam pekerjaannya maka semakin rendah niat untuk berpindah. H4 diterima dengan nilai p-value $0,048 \leq 0,05$ yang berarti semakin tinggi Training Satisfaction dapat mendukung pekerjaan yang dapat meningkatkan keterlibatan kerja, sehingga menciptakan sikap dan perilaku yang positif ditandai dengan rendahnya tingkat turnover pegawai. Selanjutnya, H5 diterima dengan p-value 0,040 $\leq 0,05$ bahwa meningkatnya sikap positif yaitu Supervisor Support akan berpengaruh pada tingginya Work Engagement yang merupakan indikator motivasi intrinsik, yang selanjutnya yang akan menghasilkan penurunan tingkat niat untuk meninggalkan organisasi.

\section{Saran}

1. Kepala Sub Bagian Kepegawaian dan Kepala Bagian Umum pada Sekretariat Direktorat Jenderal Bina Pemerintahan Desa Kementerian Dalam Negeri Republik Indonesia diharapkan lebih meningkatkan jumlah kegiatan training. Training pegawai merupakan hal penting untuk dilakukan karena sebagai salah satu cara yang efektif dalam meningkatkan kemampuan pegawai serta mendukung laju perkembangan instansi pemerintah. Kegiatan training dapat dilakukan secara berkala, misalnya saat penerimaan pegawai baru, ketika membutuhkan regenerasi pegawai, saat penerapan sistem baru, dan penerapan kebijakan instansi pemerintah yang baru.

2. Pada Direktorat Jenderal Bina Pemerintahan Desa Kementerian Dalam Negeri Republik Indonesia, pegawai bergantung kepada pimpinan dikarenakan pimpinan dapat memecahkan proses permasalahan yang ada. Di sisi lain pemimpin dapat mengetahui permasalahan secara keseluruhan dan terintegrasi yang berakibat pada pemecahan masalah yang lebih efektif. Kemudian, dengan bergantungnya kepada pimpinan, diharapkan pegawai akan mendapatkan peran dan tanggung jawab sehingga dapat memberikan solusi terhadap masalah yang sudah didiskusikan sebelumnya.

3. Diharapkan Kepala Sub Bagian Kepegawaian dan Kepala Bagian Umum, menggunakan gaya kepemimpinan yang dibutuhkan organisasi untuk memastikan agar Work Engagement memberikan efek positif pada tingkat semangat pegawai. Pemimpin transformasional memotivasi pegawai tidak hanya dengan insentif finansial, tetapi juga dengan merangsang rasa pencapaian dan penegasan diri mereka. Dukungan Kepala Sub Bagian Kepegawaian yang cukup tinggi dalam kepemimpinan 
transformasional, mampu memberdayakan pengikut mereka daripada kebutuhan mereka sendiri. Ketika digunakan dengan keyakinan pribadi, kekuasaan pemimpin menjadi sumber energi daripada sumber kontrol untuk meningkatkan keterlibatan kerja. Akibatnya, ketika gaya kepemimpinan transformasional diadopsi dalam organisasi, dukungan Kepala Bagian Umum yang ditawarkan kepada pegawai meningkat. Dengan demikian, komitmen pegawai untuk bekerja meningkat pada tingkat yang sama.

4. Untuk mencegah atau mengurangi tingkat Turnover Intention di Kementrian Dalam Negeri Bina Pemerintahan Desa, sebaiknya manajer harus lebih memperhatikan kenyamanan dan kemakmuran pegawai saat bekerja, seperti rasa adil dan kesejahteraan. Manajer juga diharapkan bisa membantu dan memberikan saran terhadap pegawai serta melibatkan pegawai dalam melakukan kegiatan-kegiatan instansi pemerintah agar pegawai tersebut tidak memiliki niat untuk berpindah kerja.

\section{Rekomendasi Penelitian Selanjutnya}

1. Penelitian selanjutnya diharapkan tidak hanya meneliti pada instansi pemerintahan, tetapi bisa dilakukan pada industri seperti, perbankan, perhotelan, rumah sakit, universitas, perusahaan manufaktur, dan lain-lain.

2. Jumlah sampel yang digunakan harus lebih banyak sehingga dapat memperoleh data yang lebih akurat.

\section{DAFTAR PUSTAKA}

Agarwal, Upasna A., and Vishal Gupta. 2018. "Relationships between Job Characteristics, Work Engagement, Conscientiousness and Managers' Turnover Intentions: A Moderated-Mediation Analysis." Personnel Review 47(2): 353-77.

AK, Belete. 2018. "Turnover Intention Influencing Factors of Employees: An Empirical Work Review." Journal of Entrepreneurship \& Organization Management 07(03): 37.

Ferdian, Ary, Bachruddin Saleh Luturlean, Khairani Ditha Zhafira, and Nabilla Kalvina Izumi. 2020. "The Impact of Work Stress on Turnover Intention in Indonesia: Is There A Mediation from Employee' Job Satisfaction?" GATR Journal of Management and Marketing Review 5(1): 31-40.

Hair JR, Joseph F., William C. Black, Barry J. Babin, and Rolph E. Anderson. 2010. Multivariate Data Analysis. 7th ed. New Jersey: Pearson Prentice Hall. 
Harahap, D. H., Tri Welas Asih, Arundati Shinta, \& Siti Mahmudah. (2016). Turnover dan Strategi Inovasi Untuk Mengatasinya. Seminar Nasional Psikologi "Aktualisasi Potensi Anak Bangsa Menuju Indonesia Emas”, 72-80.

Islam, M. Nazmul, Fumitaka Furuoka, and Aida Idris. 2020. "Transformational Leadership and Employee Championing Behavior during Organizational Change: The Mediating Effect of Work Engagement." South Asian Journal of Business Studies.

Jaworski, Caitlin, Swathi Ravichandran, Aryn C Karpinski, and Shweta Singh. 2018. "International Journal of Hospitality Management The e Ff Ects of Training Satisfaction , Employee Bene Fi Ts , and Incentives on Part-Time Employees , Commitment." International Journal of Hospitality Management 74(October 2017): $1-12$.

Kashyap, Vaneet, Neelam Nakra, and Ridhi Arora. 2021. “Do 'Decent Work' Dimensions Lead to Work Engagement? Empirical Evidence from Higher Education Institutions in India." European Journal of Training and Development.

Khan, Muhammad Mumtaz et al. 2021. "My Meaning Is My Engagement: Exploring the Mediating Role of Meaning between Servant Leadership and Work Engagement." Leadership and Organization Development Journal.

Kim, Woocheol, and Young Sup Hyun. 2017. "The Impact of Personal Resources on Turnover Intention: The Mediating Effects of Work Engagement." European Journal of Training and Development 41(8): 705-21.

Lin, Chieh Peng, Yuan Hui Tsai, and Ferdinandus Mahatma. 2017. "Understanding Turnover Intention in Cross-Country Business Management." Personnel Review 46(8): 1717-37.

Ling Suan, Choo, and Aizzat Mohd Nasurdin. 2016. "Supervisor Support and Work Engagement of Hotel Employees in Malaysia: Is It Different for Men and Women?" Gender in Management 31(1): 2-18.

$\mathrm{Lu}, \mathrm{Lu}$, Allan Cheng Chieh Lu, Dogan Gursoy, and Nathan Robert Neale. 2016. "Work Engagement, Job Satisfaction, and Turnover Intentions: A Comparison between Supervisors and Line-Level Employees." International Journal of Contemporary Hospitality Management 28(4): 737-61.

Memon, Mumtaz Ali et al. 2021. "Satisfaction Matters: The Relationships between HRM Practices, Work Engagement and Turnover Intention." International Journal of Manpower 42(1): 21-50.

Memon, Mumtaz Ali, Rohani Salleh, and Mohamed Noor Rosli Baharom. 2020. "The Link between Training Satisfaction, Work Engagement and Turnover Intention." European Journal of Training and Development 40(6): 407-29.

Pattnaik, Subash Chandra, and Narendra Panda. 2020. "Supervisor Support, Work Engagement and Turnover Intentions: Evidence from Indian Call Centres." Journal of Asia Business Studies 14(5): 621-35.

Rahman, Mantep Fauzi, and Evi Susanti. 2021. "International Journal of Multicultural and Multireligious Understanding The Role of Training Satisfaction and Work Engagement on Employee ' s OCB." (2007): 44-54.

Sawasdee, Aksorn, Sakapas Saengchai, and Kittisak Jermsittiparsert. 2020. "The Role of Emotional Demands, Supervisor Support and Training Opportunities towards Work 
Engagement among Employees in Pharmaceutical Companies of Thailand." Systematic Reviews in Pharmacy 11(3): 176-84.

Sekaran, Uma. 2006. Metode Penelitian Untuk Bisnis. 4th ed. Jakarta: Salemba Empat.

Sekaran, Uma and Roger Bougie. 2017. Metode Penelitian Untuk Bisnis. 6th ed. Jakarta: Salemba Empat.

Sugiyono. 2010. Metode Penelitian Pendidikan Pendekatan Kuantitatif, Kualitatif, Dan $R \& D$. Bandung: Alfabeta.

Wirawan, Hillman, Muhammad Jufri, and Abdul Saman. 2020. "The Effect of Authentic Leadership and Psychological Capital on Work Engagement: The Mediating Role of Job Satisfaction." Leadership and Organization Development Journal 41(8): 1139-54.

Yucel, Ilhami. 2021. "The Mediating Effect of Work Engagement on the Relationship between Work - Family Conflict and Turnover Intention and Moderated Mediating Role of Supervisor Support during Global Pandemic."

Zhang, Wenjie, Hongdao Meng, Shujuan Yang, and Danping Liu. 2018. "The Influence of Professional Identity, Job Satisfaction, and Work Engagement on Turnover Intention among Township Health Inspectors in China." International Journal of Environmental Research and Public Health 15(5).

\section{Website}

https://www.catalyst.org/research/turnover-and-retention/ (Diakses pada 5 Juni 2021)

http://www.binapemdes.kemendagri.go.id/ (Diakses pada 29 Juli 2021) 